\title{
Resect them all
}

\author{
Yutaka Okita, MD, PhD
}

\author{
From the Division of Cardiovascular Surgery, Department of Surgery, Kobe University, Kobe, Hyogo, Japan. \\ Disclosures: Author has nothing to disclose with regard to commercial support. \\ Received for publication April 17, 2016; accepted for publication April 18, 2016; available ahead of print June 1, \\ 2016. \\ Address for reprints: Yutaka Okita, MD, PhD, Division of Cardiovascular Surgery, Department of Surgery, Kobe \\ University, Kobe, Hyogo, Japan (E-mail: yutakaokita@gmail.com). \\ J Thorac Cardiovasc Surg 2016;152:437-8 \\ 0022-5223/ $\$ 36.00$ \\ Copyright (C 2016 by The American Association for Thoracic Surgery \\ http://dx.doi.org/10.1016/j.jtcvs.2016.04.060
}

Kunihara et $\mathrm{al}^{1}$ have been publishing tremendous information regarding aortic root and cusp anatomy, physiology, and surgery for annuloaortic ectasia or aortic cusp abnormalities during the past 2 decades. I admire their continuing efforts to establish surgical strategy in this field. In a current article, ${ }^{1}$ they report on the usefulness of aortic root remodeling technique in patients with acute aortic dissection and aortic root enlargement. This is the largest series of aortic root remodeling procedure applied in patients with acute aortic dissection. In 59 out of 215 patients with acute aortic dissection, remodeling root procedure was performed with early mortality of $6.8 \%$ and with freedom from proximal reoperation rate of $98 \%$ at 10 years. I commend the authors for achieving superb results even in a life-threatening situation. It is a great honor to discuss this article.

Sometimes patients with acute type A aortic dissection present with serious complications, such as cardiac tamponade and shock state, stroke or transient ischemic attack, myocardial infarction, or mesenteric or limb ischemia. In this series, 57 patients underwent surgery within 12 hours after onset of aortic dissection. One-third of patients had cardiac tamponade and one-quarter had organ malperfusion. A simpler approach-replacing the ascending aorta and stabilizing the proximal dissection with supracoronary anastomosis - usually has been applied in such devastating situations. But these authors' approach seems to be more aggressive: Resect all proximal dissected tissue. We have not seen many articles dealing with valve-sparing technique with aortic root replacement in acute aortic dissection. ${ }^{2-6}$ It would be interesting for readers to know the authors' threshold for going further to aortic root procedures in complicated aortic dissection. How many acute aortic dissection patients with preexisting root dilatation did not undergo aortic root replacement?

One difficulty exists in measuring the precise diameter of the aortic root in the setting of acute aortic dissection. The authors used transesophageal echocardiography to measure the diameter of the aortoventricular junction, sinus of Valsalva, and sinotubular junction; however, it is sometimes difficult to measure by echocardiography alone, especially assessing the sinotubular junction. We need some

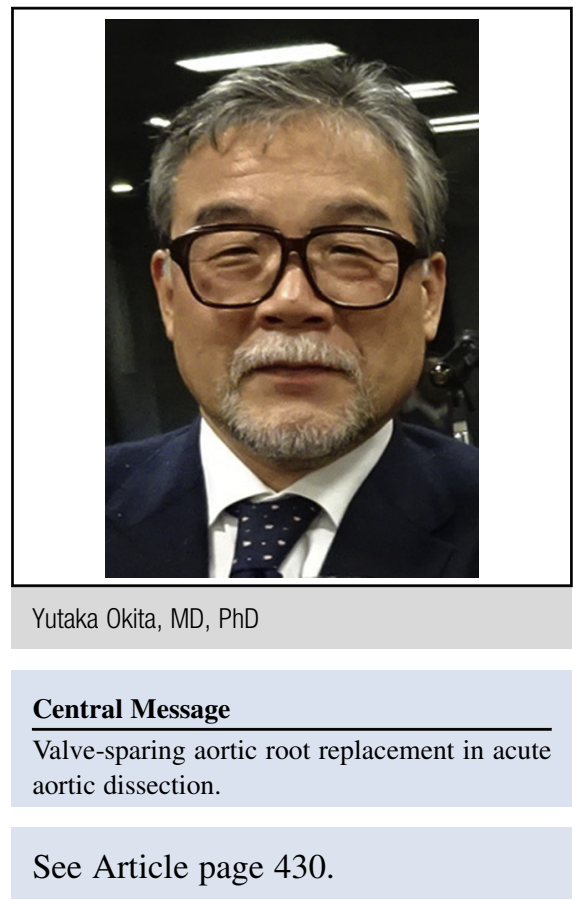

information measured by computed tomography scan in each dimension of the aortic root. The aortic root does increase its diameter after the onset of acute aortic dissection as the false lumen expands. Considering the patients' ages, excluding 3 Marfan patients, setting the criterion of root dilatation at 43 to $45 \mathrm{~mm}$ is not so exclusive; however, the aortoventricular junction diameter $(28 \mathrm{~mm})$ was quite large, and needs stabilization. Also, they have some room for decision based on a patient's body size $(<42-45$ not dilated and $\geqq 43-45 \mathrm{~mm}$ dilated). I presume that they finally used an eyeball decision by the senior surgeon for root replacement.

It is curious that half of patients had cusp prolapse and needed central plication of the aortic cusps. Usually, aortic regurgitation is caused by dissected commissure and resultant cusp prolapse, but once the aortic root is stabilized, aortic cusp rarely requires plication technique to correct its prolapse. This might not be the case in this cohort because patients had "preexisting root dilatation."1 Of course, every bicuspid valve needs some degree of plication, but some possibilities remain of causing de novo aortic cusp prolapse by the remodeling technique itself.

Another issue is how to fix the detached commissure between the left and noncoronary sinus. Some advanced aortic dissection extends beyond the aortic cusp attachment and runs deeply into near the aortoventricular junction posteriorly. The commissure between the left and noncoronary 
cusp shows complete detachment of this commissure causing severe aortic regurgitation. The technique of these authors was "the stitches were carefully placed through the dissected inner layer and the adventitia" ${ }^{1}$ without using polytetrafluoroethylene reinforcement or biological glue. I think this technique is not reproducible by every surgeon. Furthermore, the incidence of reoperation for bleeding was rather high compared with other experiences. On the other hand, reimplantation technique has some advantages because the whole aortic tissue was included within the graft by a double-layered sutures.

Although the multivariate analysis was not significant, Marfan syndrome, the diameter of the sinotubular junction, and diameter of the sinus Valsalva turned out to be risk factors for late proximal reoperation in univariate analysis. I have some concerns for the long-term fate of annular stability by remodeling technique only in these patients. They started to use annular stitches using polytetrafluoroethylene sutures, but it is premature to decide the effectiveness of this procedure.
Again, I congratulate the authors for achieving superb results in dealing with difficult problems.

\section{References}

1. Kunihara T, Neumann N, Kriechbaum SD, Aicher D, Schäfers HJ. Aortic root remodeling leads to good valve stability in acute aortic dissection and preexistent root dilatation. J Thorac Cardiovasc Surg. 2016;152:430-6.e1.

2. Leyh RG, Fischer S, Kallenbach K, Kofidis T, Pethig K, Harringer W, et al. High failure rate after valve-sparing aortic root replacement using the "remodeling technique" in acute type A aortic dissection. Circulation. 2002;106: I229-33.

3. Erasmi AW, Stierle U, Bechtel JF, Schmidtke C, Sievers HH, Kraatz EG. Up to 7 years' experience with valve-sparing aortic root remodeling/reimplantation for acute type A dissection. Ann Thorac Surg. 2003;76:99-104.

4. Subramanian S, Leontyev S, Borger MA, Trommer C, Misfeld M, Mohr FW. Valve-sparing root reconstruction does not compromise survival in acute type A aortic dissection. Ann Thorac Surg. 2012;94:1230-4.

5. Leshnower BG, Myung RJ, McPherson L, Chen EP. Midterm results of David V valve-sparing aortic root replacement in acute type A aortic dissection. Ann Thorac Surg. 2015;99:795-800.

6. Masuda M, Kuwano H, Okumura M, Arai H, Endo S, Doki Y, et al. Thoracic and cardiovascular surgery in Japan during 2013. Annual report by The Japanese Association for Thoracic Surgery. Gen Thorac Cardiovasc Surg. 2015; 63:670-701. 